\title{
BMJ Open Connor-Davidson Resilience Scale: validation study in a Portuguese sample
}

\author{
Joana Faria Anjos, ${ }^{\oplus 1,2}$ Maria João Heitor dos Santos, ${ }^{\circledR 3,4}$ Maria Teresa Ribeiro, \\ Sergio Moreira ${ }^{1}$
}

To cite: Faria Anjos J, Heitor dos Santos MJ, Ribeiro MT, et al. Connor-Davidson Resilience Scale: validation study in a Portuguese sample. BMJ Open 2019;9:e026836. doi:10.1136/ bmjopen-2018-026836

- Prepublication history for this paper is available online To view these files, please visit the journal online (http://dx.doi. org/10.1136/bmjopen-2018026836).

Received 21 September 2018 Revised 14 March 2019 Accepted 28 March 2019
Check for updates

\section{Author(s) (or their} employer(s)) 2019. Re-use permitted under CC BY-NC. No commercial re-use. See rights and permissions. Published by BMJ.

${ }^{1} \mathrm{CICPSI}$, Faculdade de Psicologia, Universidade de Lisboa, Lisboa, Portugal ${ }^{2}$ Instituto Nacional de Emergência Médica, IP, Portugal ${ }^{3}$ Instituto de Medicina Preventiva e Saúde Pública and Instituto de Saúde Ambiental, Faculdade de Medicina, Universidade de Lisboa, Lisboa, Portugal

${ }^{4}$ Psiquiatria e Saúde Mental, Hospital Beatriz Angelo, Loures, Portugal

Correspondence to Dr Joana Faria Anjos; joana.f.anjos@gmail.com

\section{ABSTRACT}

Objective The objective of this paper was to evaluate the structural validity and convergent validity of the first Portuguese version of the Connor-Davidson Resilience Scale (CD-RISC).

Settings The data sets come from two studies conducted in Portugal, respectively, from the Resilience Effect in Coping with Trauma (RECT) project and from the Health Impact Assessment of Employment Strategies (HIAES) project.

Participants The sample is composed of 476 participants from the RECT project and 405 participants from the HIAES project. In both projects, convenience samples were used. Measures The original CD-RISC items were translated to Portuguese and were used in a survey along with additional psychosocial and biomedical measures. Results Independent exploratory factorial analysis (EFA) with each of the two samples revealed that the best solution in both samples had three factors consistent with the self-efficacy, spirituality and social support factors from the original scale. A Confirmatory factor analysis using the two samples together and specifying the three factors from the EFA revealed a good overall fit and, comparatively, better fit than a model specified with the five factors from the original scale. The study of the convergent validity revealed that bivariate correlations between the three factors and validated measures of stress, life satisfaction, mental health and physical health are globally consistent with previous research.

Conclusions This study makes available to the broad Community of Portuguese Language Countries a validated measure of resilience extensively used for research and intervention. The results encourage future studies using this translated version of CD-RISC to explore further the three-factor structure found here and to test the convergent validity with new samples.

\section{INTRODUCTION}

Resilience can be described as a dynamic process of adaptively overcoming stress and adversity while maintaining normal psychological and physical functioning, and not merely the absence of psychopathology. ${ }^{1}$ As an individual characteristic, resilience is likely influenced by external variables, such as adequate social support, that reduce risk for stress-related mental disorders by buffering the impact of stress. ${ }^{2}$
Strengths and limitations of this study

Uses a large sample of Portuguese participants studied with rigorous data collection protocols that provide the right context to test the Connor-Davidson Resilience Scale (CD-RISC) psychometric properties in the context of the Portuguese population.

- Applies sound validated data analysis methodologies (following Green and colleagues) for testing the structural validity.

- Makes available a tested (and validated by the original CD-RISC authors) translated version to the Portuguese-speaking community.

- Has two different samples, requiring the adaptation of commonly used psychometric analysis.

- The two different samples also resulted in differences in test power for the convergent validity analysis.

In a quantitative methodological review for searching, screening and appraising resilience scales quality, the Connor-Davidson Resilience Scale (CD-RISC), the Resilience Scale for Adults and the Brief Resilience Scale received the best psychometric ratings. ${ }^{3}$

Based on the perspective that resilience is a personal quality that reflects the ability to cope with stress, Connor and Davidson ${ }^{4}$ developed a brief self-report scale to quantify resilience. The original version of CD-RISC has 25 self-rated items; each of them rated a 5-point scale from 0 ('not true at all') to 4 ('true nearly all the time'). Despite the absence of a proposed cut-off value, higher scores represent higher resilience. The CD-RISC was developed with participants from different settings, including the general population, primary care outpatients, psychiatric inpatients and clinical trial patients. ${ }^{4}$ The CD-RISC is a generic measure that can be applied to different populations since it was not developed for a specific group. ${ }^{5}$ The original study demonstrated solid psychometric properties, with good internal consistency and test-retest reliability, with validity being demonstrated with other measures of stress and hardiness. ${ }^{4}$ It suggested that resilience is modifiable and can improve with treatment. 
Further research on violent trauma showed that survivors who exhibit better health or less distress from the trauma are more resilient. ${ }^{6}$

The CD-RISC has been translated into over 50 languages and has been tested in several different contexts and specific populations: on the general population, ${ }^{7-9}$ post-9/11 US military veterans, ${ }^{10}$ United States Air Force,${ }^{11}$ adolescents, ${ }^{12}$ university students, ${ }^{13}{ }^{14}$ young adults, ${ }^{15}$ older adults, ${ }^{16}$ earthquake survivors, ${ }^{5}$ adolescent earthquake survivors,,${ }^{17}$ homeless youth,${ }^{18}$ caregivers with chronic stress, ${ }^{19}$ people with spinal cord injuries, ${ }^{20}$ rehabilitation patients after unintentional injury ${ }^{21}$ and sport performers, ${ }^{22}$ among many others.

Preliminary studies of the scale revealed that the CD-RISC has a multifactorial structure. Connor and Davidson ${ }^{4}$ performed exploratory factorial analysis (EFA) using the adults sample from general population. The factor analyses yielded five factors, named as personal competence, high standards and tenacity; trust in one's instinct, tolerance of negative affect and strengthening effects of stress; positive acceptance of change and secure relationships with others; control and spiritual influences. Nevertheless, the CD-RISC factor structure still needs to be clarified since subsequent studies found different factor structures.

Prince-Embury ${ }^{23}$ suggests that the instability of factor structures might have been related to insufficient numbers of items covering various aspects of the original construct and that factor structure differences would be expected in studies of groups that varied culturally and demographically.

Therefore, the objective of this study was to evaluate the psychometric properties of the CD-RISC Portuguese version, with the aim of determining whether it can be used as a reliable and valid tool to assess Portuguese population resilience.

\section{METHODS}

The study of CD-RISC psychometric properties and convergent validity was conducted with data sets coming from two studies.

The first data set came from the Resilience Effect in Coping with Trauma (RECT) research project in Portugal, conducted at the Faculty of Psychology of the University of Lisbon. The second data set came from the Health Impact Assessment of Employment Strategies (HIAES) project in Portugal. It was approved by the National Commission of Data Protection.

\section{Sample}

The RECT project has a convenience sample of 476 participants $(44 \%$ female participants) composed of master students, a technical course of medical emergency students and the general population. Participants from the HIAES project consist of 405 workers $(51 \%$ female participants) at a private financial institution and is also a convenience non-probabilistic sample. Descriptive data from the two samples for general sociodemographic variables show noteworthy differences in age and education. Regarding the age of the participants, the mean for the RECT sample was 26 ( $\mathrm{SD}=6.24)$, while the mean for the HIAES project was 41 ( $\mathrm{SD}=8.3)$. Concerning the education variable, the RECT project's sample was composed mostly of participants with a high school degree $(58 \%)$, followed by middle school (27\%) and graduate or higher (15\%) degrees. The HIAES project's sample, however, had a higher percentage of participants with a graduate or higher degree $(69 \%)$, followed by high school $(30 \%)$ and middle school (1\%) degrees.

\section{Instruments}

Besides the CD-RISC, we also collected data for a set of other measures relevant to each project objective. In this section, we only describe the CD-RISC and the measures relevant to test for convergent validity. It is important to note that different data were collected in each of the samples and, also, for different groups within each sample.

\section{Connor-Davidson Resilience Scale}

The CD-RISC ${ }^{4}$ is a scale developed to quantify psychological resilience and the clinical effects of the treatment of anxiety and depression. It is composed of 25 items measured using a 5-point scale $(0=$ not true to $4=$ almost always true), and the original study describes five factors: the notion of personal competence, high standards and tenacity; trust in one's instincts, tolerance of negative affect and strengthening effects of stress; positive acceptance of change and secure relationships; control and, finally, spiritual influences. Despite Connor and Davidson's original study corroborating these five factors, latter studies have reported support for only one factor. ${ }^{5}$

\section{Additional measures}

An additional set of eight measures was collected for these two studies. More specifically, in the RECT project, the following measures were collected:

- Social Provisions Scale (SPS), an instrument that measures perceived social support. ${ }^{24}$ Here we used the Portuguese version developed by Moreira and Canaipa. ${ }^{25}$

- Satisfaction With Life Scale (SWLS), an instrument that measures life satisfaction based on the subjective judgement done by each person, accordingly to his own pattern of life satisfaction. ${ }^{26}$ We used the Portuguese adaptation of the scale conducted by Simões. ${ }^{27}$

- Perceived Stress Scale (PSS-10), a reduced version of the Perceived Stress Scale, ${ }^{28} 29$ an instrument used to measure the perception of stress. We used the Portuguese adaptation of the PSS-10 described by Rocha. ${ }^{30}$

- Stress Vulnerability Questionnaire (23QVS), a measure of the individual's vulnerability to stress. ${ }^{31}$

In the HIAES project, four additional measures were collected:

- Health and lifestyle (H\&LS) information regarding perceived health (measured using a single item-'How 
would you classify your general health state during the last 3 months?'-and a 3-point Likert scale), the practice of physical exercise (measured using both a practice frequency and a practice quality scales) and medication consumption (Mcons) (measured using a dichotomous scale-yes vs no-for a set of 14 clinical conditions).

- Biomedical Index (BI) measured by means of blood samples, anthropometric parameters and blood pressure.

- Mental Health Inventory (MHI-5), the reduced version of the Mental Health Inventory ${ }^{32}$ that measures psychological stress and well-being using five items and a frequency scale of $1=$ always to $6=$ never. Here, we used a Portuguese adaptation of the MIH-5 described by Ribeiro. ${ }^{33}$

- Subjective Happiness Scale (SHS), a measure of subjective happiness originally developed by Lyubomirsky and Lepper, ${ }^{34}$ composed of four items responded to on a 7-point Likert scale. Again, we used a Portuguese version described by Pais-Ribeiro. ${ }^{35}$

\section{Procedure}

Translation and adaptation to the Portuguese language

The CD-RISC items were translated through a process of translation and back-translation from the original American scale ${ }^{4}$ by specialists in psychology who were fluent in both Portuguese and English, and were finally approved by the original CD-RISC authors.

\section{Survey procedure}

For the RECT data, a survey was conducted between April 2009 and May 2010. The questionnaires were administered in paper-and-pencil format. This was done either face-to-face or administered in a classroom context. The CD-RISC was completed by 421 participants, while the additional convergent validity measures were completed by 55 participants.

For the HIAES data, a survey was conducted between November 2012 and June 2013. The survey had two parts: the first part of the survey, with sociodemographic information and H\&LS, MHI-5 and SHS scales, was completed electronically, while in the second part, the participants completed the CD-RISC in paper and pencil format. Additionally, for a subsample of 260, anthropometric measures and blood samples were collected.

All the participants from both research projects were informed of the investigation and gave their signed informed consent. The participants were not involved in the design and planning of the study.

\section{Structural validity}

The main objective of this paper was to study the structural validity of the Portuguese version of the CD-RISC. We followed Green and colleagues ${ }^{, 10}$ procedure where an EFA was used to test the factorial structure of the original 25-item five-factor solution version of the CD-RISC, and afterwards, a confirmatory factor analysis (CFA) was used to compare a proposed solution based on the EFA results with Connor and Davidson's original one. We note that this methodology used by Green and colleagues is particularly suited for our type of data. More specifically, this methodology allows understanding of the specific behaviour of the items in each of the two samples and only then to test the factorial structure of the scale with the complete sample.

Two independent EFAs were conducted in each one of the two data sets. In this analysis, the following criteria were taken into account. First, to determine the number of factors, we considered the criterion of an eigenvalue higher than 0.7. Second, for the interpretation of the items in each factor, the rotational oblimin solutions were considered, since the factors are expected to correlate with each other. Additionally, for an item to be held for a particular factor, communalities should be higher than 0.09 , loadings should be equal to or higher than 0.32 , and also cross-loadings should be lower than $0.32 .{ }^{36}$ Finally, the resulting items in a factor were tested for internal consistency using Cronbach's alpha.

Following the EFA, two CFAs were conducted using the complete sample to test and compare both the proposed solution as specified by EFA and the original 25-item five-factor solution. The statistical quality of the models was assessed using two sets of measures. First, the overall goodness of fit was measured considering the following criteria: Standardized Root Mean Square Residual (SRMR) and Root Mean Square Error of Approximation (RMSEA) lower or equal to 0.08, Comparative-Fit Index (CFI) and Tucker-Lewis Index (TLI) higher or equal to 0.90. Additionally, the localised areas of strain were measured with the following criteria: standardised residuals lower or equal to 2.58 and general modification index analysis lower or equal to 4 .

Both analyses used pairwise deletion for missing data. Results were compared with a mean replacement method and no differences were found.

\section{Convergent validity}

Another aim of the present paper was to provide data for the convergent validity of the CD-RISC. The convergent validity is a form of validation that tests for the association between a construct measured by a scale and other measures that theoretically relate to this construct. ${ }^{3738}$ For the convergent validity of the CD-RISC, variables used in the survey of the HIAES and RECT projects were selected and bivariate correlations were computed. First, due to the sample dimension and the characteristics of the variables studied, only correlations with a $\mathrm{p}$ value equal to or lower than 0.01 were considered statistically significant. ${ }^{39}$ Second, for the interpretation, we considered correlation values inferior to 0.20 as weak correlations, correlation values between 0.20 and 0.60 as moderate correlations, and correlation values higher than 0.60 as strong correlations. 


\section{Patient and public involvement}

The patients and the public were not involved in the conception, design or interpretation of this study.

\section{RESULTS}

\section{Structural validity}

\section{Exploratory Factorial Analysis}

The first set of EFAs was conducted on each data sample, forcing the 25-items to the original five-factor solution and, following Karairmak ${ }^{5}$ and Burns and Anstey, ${ }^{15}$ to three-factor and one-factor solutions. The results on both data set indicated that none of the solutions replicated corresponding results. In fact, the factor structure for the five-factor and three-factor solutions did not hold, and for the three solutions tested, several items revealed low communalities, low loadings and cross-loadings in both samples. In line with this, items 5, 11, 12, $14,17,20$ and 23 were excluded because of systematic problems in the different solutions. A second set of EFAs was conducted with the 18 items for each data sample. Once the original five-factor and three-factor solutions could no longer be interpreted, we used the scree plot to choose the best solution. The results on both data sets showed that the best solution had three factors, but items 22 and 25 still revealed problematic. A final set of EFAs was conducted with the 16 items. Results showed that the best solution in both samples had three factors with $37 \%$ and $31 \%$ of explained variance, respectively (tables 1 and 2). Factor 1 was the most representative factor, composed of 11 items and explained $20 \%$ and $16 \%$ of variance, respectively, and an alpha of 0.82 and 0.76 . This factor, which we labelled self-efficacy, describes individuals' beliefs about not only their personal competence while dealing with challenging demands but also their ability to exercise control over their own functioning. Factor 2 was composed of three items and explained 9\% and $8 \%$ of variance, respectively, and an alpha of 0.71 and 0.67. This factor was named spirituality and evaluates specific aspects of spirituality, namely, the belief that life has a purpose and that spiritual forces can influence earthly events. Finally, factor 3 was composed of two items and explained $8 \%$ and $7 \%$ of variance, respectively, and an alpha of 0.53 and 0.44 . This factor refers to the perceived social support and evaluates how people perceive their reliance on others for emotional and functional support. We note that the alphas for self-efficacy and spirituality are above 0.7 . Also, for social support, once there were only two items, we used bivariate correlations. Here, the results showed a moderate association between the two items.

Table 1 Factorial weights of the 16 items on each of the three factors and respective explained variance for the Resilience Effect in Coping with Trauma sample

\begin{tabular}{llccc}
\hline $\begin{array}{l}\text { Items/explained } \\
\text { variance }\end{array}$ & Communalities & Self-efficacy & Spirituality & Social support \\
\hline 19 & 0.44 & 0.65 & 0.05 & 0.11 \\
24 & 0.28 & 0.47 & 0.20 & 0.10 \\
15 & 0.33 & 0.57 & -0.01 & 0.08 \\
18 & 0.28 & 0.52 & -0.07 & 0.06 \\
\hline 7 & 0.35 & 0.53 & -0.01 & 0.28 \\
8 & 0.33 & 0.56 & 0.08 & 0.11 \\
1 & 0.30 & 0.52 & 0.04 & 0.14 \\
16 & 0.30 & 0.53 & 0.01 & 0.14 \\
4 & 0.40 & 0.61 & 0.14 & 0.00 \\
\hline 6 & 0.24 & 0.39 & 0.16 & 0.25 \\
10 & 0.18 & 0.35 & 0.20 & 0.11 \\
\hline 9 & 0.50 & 0.10 & 0.69 & 0.08 \\
21 & 0.45 & 0.14 & 0.60 & 0.28 \\
\hline 3 & 0.48 & -0.06 & 0.69 & 0.02 \\
\hline 2 & 0.38 & 0.18 & 0.13 & 0.58 \\
\hline 13 & 0.72 & 0.17 & 0.16 & 0.82 \\
\hline Variance explained & - & $20 \%$ & $9 \%$ & $8 \%$ \\
Alpha & - & 0.82 & 0.71 & $0.53^{*}$ \\
\hline M (SD) & - & $2.92(0.54)$ & $2.64(0.91)$ & $3.14(0.83)$ \\
\hline $\mathrm{n}$ & - & 421 & 421 & 421 \\
\hline Cor & - & & \\
\hline
\end{tabular}

${ }^{*}$ Correlation for the two items, $p<0.05$. 
Table 2 Factorial weights of the 16 items on each of the three factors and respective explained variance for the Health Impact Assessment of Employment Strategies sample

\begin{tabular}{|lllll}
\hline Items/explained variance & Communalities & Self-efficacy & Spirituality & Social support \\
\hline 19 & 0.36 & 0.58 & -0.07 & 0.13 \\
24 & 0.33 & 0.57 & 0.02 & 0.09 \\
15 & 0.32 & 0.56 & -0.04 & 0.07 \\
18 & 0.28 & 0.52 & -0.07 & 0.07 \\
\hline 7 & 0.26 & 0.51 & 0.08 & 0.02 \\
8 & 0.24 & 0.48 & 0.04 & 0.08 \\
\hline 1 & 0.26 & 0.43 & 0.06 & 0.27 \\
16 & 0.19 & 0.43 & 0.08 & 0.04 \\
\hline 4 & 0.16 & 0.38 & 0.04 & 0.13 \\
\hline 6 & 0.12 & 0.33 & 0.12 & 0.05 \\
\hline 10 & 0.18 & 0.33 & 0.19 & 0.19 \\
\hline 9 & 0.52 & 0.08 & 0.72 & 0.00 \\
\hline 21 & 0.37 & 0.09 & 0.60 & 0.07 \\
\hline 3 & 0.36 & -0.06 & 0.59 & 0.13 \\
\hline 2 & 0.59 & 0.09 & 0.06 & 0.76 \\
\hline 13 & 0.35 & 0.21 & 0.14 & 0.54 \\
\hline Variance explained & - & $16 \%$ & $8 \%$ & $7 \%$ \\
\hline M (SD) & - & 0.76 & 0.67 & $0.44^{\star}$ \\
\hline $\mathrm{n}$ & - & $3.03(0.40)$ & $2.47(0.84)$ & $3.24(0.67)$ \\
\hline
\end{tabular}

${ }^{*}$ Correlation for the two items, $p<0.05$.

A descriptive analysis of the three subscales showed that the average results for self-efficacy were above the midpoint of the scale and had small SDs on both RECT and HIAES samples, $2.92(\mathrm{SD}=0.54)$ and $3.03(\mathrm{SD}=0.40)$, respectively. The same applied to the average results and SDs of the spirituality subscale, $2.64(\mathrm{SD}=0.91)$ and $2.47(\mathrm{SD}=0.84)$, respectively, and of the social support subscale, 3.14 $(\mathrm{SD}=0.83)$ and $3.24(\mathrm{SD}=0.67)$, respectively.

\section{Confirmatory factorial analysis}

CFA was conducted to test the model specified by EFA and to compare this model with the one suggested by Connor and Davidson's original five-factor solution. Considering the meaning of both the proposed three-factor solution and the original five-factor solution, in both cases, the CFAs were computed, allowing for factors to correlate among themselves.

A preliminary analysis of the frequency distributions and statistics for skewness and kurtosis of CD-RISC showed severe negative asymmetry of the data in most of the 25 items. To reduce the impact of the data distributions on the model computations, we log transformed all the data (note that the data were previously transformed to eliminate 0 values by adding a constant, and afterwards all the results were inverted). The asymmetry of the resulting $\log$ transformed frequency distributions for the 25 items was significantly reduced and consequently used in the CFA.

The results for the proposed 16-item three-factor solution revealed a good overall fit, $\chi^{2}(101)=368.64, \mathrm{p}<0.001$; $\mathrm{SRMR}=0.05$, RMSEA $=0.06 \quad(0.05,0.06), \mathrm{CFI}=0.90$ and $\mathrm{TLI}=0.89$. The analysis also showed that few standardised residuals were higher than 2.58 , and, similarly, few modification indexes were above 4 . Finally, all items were highly correlated with their factors, with all correlations between 0.40 and 0.77 and all $p$ values $<0.001$.

The results for the original 25-item five-factor solution revealed a moderate overall fit, with both CFI and TLI measures slightly below the criteria, $\chi^{2} \quad(263)=1219.08$, $\mathrm{p}<0.001 ; \quad \mathrm{SRMR}=0.06, \quad \mathrm{RMSEA}=0.07 \quad(0.06, \quad 0.07)$, $\mathrm{CFI}=0.82$ and $\mathrm{TLI}=0.79$. Additionally, the analysis also showed several standardised residuals above the criteria, and, similarly, several modification indexes were above 4 . All items were significantly correlated with their factors (all $\mathrm{p}$ values $<0.001$ ), but correlations ranged between a weak 0.20 and a strong 0.70 . Overall, the proposed 16 -item three-factor solution had better performance in the CFA.

\section{Convergent validity}

Six of the eight measures used to test the convergent validity (ie, SPS, SWLS, PSS-10, 23QVS, MHI-5 and SHS) were tested for the structural validity on their 
Table 3 Descriptives (mean, SD and sample size) of the measures used to test the convergent validity

\begin{tabular}{lccc}
\hline & M & SD & n \\
\hline SPS & 8.75 & 9.36 & 53 \\
SWLS & 24.72 & 5.26 & 54 \\
PSS-10 & 14.51 & 5.49 & 55 \\
23QVS & 28.67 & 9.44 & 55 \\
H\&LS & & & \\
Phea & 1.38 & 0.52 & 405 \\
Pact & 3.17 & 1.45 & 405 \\
Mcons & 2.58 & 1.67 & 405 \\
BI & & & \\
Met & 0.12 & 0.32 & 260 \\
Card & 3.31 & 2.03 & 450 \\
MHI-5 & 68.91 & 18.97 & 405 \\
SHS & 5.24 & 1.08 & 405 \\
\hline
\end{tabular}

23QVS, Stress Vulnerability Questionnaire; BI, Biomedical I ndex; Card, index for cardiovascular risk; H \& LS, h ealth and life style; Mcons, medication consumption; Met, metabolic syndrome; MHI5, Five-Item Mental Health Inventory; Pact, physical activity; Phea, physical health; PSS-10, 10-Item Perceived Stress Scale; SHS, Subjective Happiness Scale; SPS, Social Provisions Scale; SWLS, Satisfaction With Life Scale.

unidimensional versions (table 3). Results from all levels of explained variance were above $40 \%$, and all Cronbach alphas were above 80 . The sole exception to these results is the 23QVS, with a somewhat lower explained variance of $23 \%$ and an alpha of 0.76 . Additionally, for the H\&LS, we considered a single item on physical health (Phea) and two indexes, one on physical activity (Pact) using the average of the frequency of Pact and of commitmentto the Pact, and an index on Mcons, consisting of the sum of the answers for Mcons regarding 14 clinical conditions. Finally, for the BI, we computed an index to identify the presence of metabolic syndrome (Met) using the recommendations of the European Society of Cardiology (http://www.escardio.org) and an index for cardiovascular risk (Card) based on the norms of the Portuguese Society of Cardiology (www.spc.pt).

Bivariate correlations were computed between each one of the three subscales, computed based on the 16 items in the CD-RISC and each of the eight measures described above and used to test the convergent validity (table 4 ). The self-efficacy factor showed a significant negative association with the two measures of stress considered: perceived stress $(\mathrm{r}=-0.32)$ and vulnerability to stress $(\mathrm{r}=-0.34)$. There were positive correlations between the self-efficacy factor and two additional variables, namely, subjective happiness $(\mathrm{r}=0.31)$ and mental health $(\mathrm{r}=0.35)$. Although moderately, the self-efficacy factor as a significant and negative correlation with Phea $(\mathrm{r}=-0.17)$ and Mcons ( $\mathrm{r}=-0.13)$ ('Note that Phea is measured using
Table 4 Bivariate correlation coefficients between the CDRISC and the measures used to test the convergent validity

\begin{tabular}{|c|c|c|c|}
\hline & 1 & 2 & 3 \\
\hline 1. Self-efficacy & - & $0.13^{\star \star \star}$ & $0.33^{\star \star *}$ \\
\hline 2. Spirituality & $0.13^{\star * \star}$ & - & $0.21^{* \star *}$ \\
\hline 3. Social support & $.33^{\star \star \star}$ & $0.21^{\star \star \star}$ & - \\
\hline H\&LS-Phea & $-0.16^{\star \star \star}$ & -0.01 & -0.09 \\
\hline H\&LS-Pact & 0.08 & 0.00 & 0.08 \\
\hline H\&LS-Mcons & $-0.13^{\star \star *}$ & 0.08 & -0.04 \\
\hline BI-Met & -0.04 & 0.02 & $-0.13^{\star *}$ \\
\hline Bl-Card & 0.07 & 0.01 & $-0.10^{\star *}$ \\
\hline MHI-5 & $0.35^{\star \star \star}$ & 0.02 & $0.26^{\star \star \star}$ \\
\hline SHS & $0.31^{\star \star *}$ & 0.09 & $0.30^{\star \star \star}$ \\
\hline SPS & 0.16 & -0.13 & $0.48^{\star \star *}$ \\
\hline SWLS & $0.28^{\star \star}$ & 0.10 & 0.11 \\
\hline PSS-10 & $-0.32^{\star \star}$ & 0.14 & 0.10 \\
\hline 23QVS & $-0.34^{\star \star}$ & $.25^{*}$ & $-0.24^{*}$ \\
\hline
\end{tabular}

${ }^{*} \mathrm{P}<0.06,{ }^{* *} \mathrm{P}<0.05,{ }^{* * *} \mathrm{P}<0.01$.

23QVS, Stress Vulnerability Questionnaire; BI, Biomedical I ndex; Card, index for cardiovascular risk; CD-RISC, Connor-Davidson Resilience Scale; H \& LS, health and life style; Mcons, medication consumption; Met, metabolic syndrome; MHI-5, Five-Item Mental Health Inventory; Pact, physical activity; Phea, physical health; SHS, Subjective Happiness Scale; SPS, Social Provisions Scale; SWLS, Satisfaction With Life Scale.

a single item where the higher the value the lower the Phea reported').

The spirituality factor showed only a marginal significant correlation with the vulnerability to stress measure $(\mathrm{r}=0.25)$.

The social support factor showed a moderate significant correlation $(\mathrm{r}=0.48)$ with the $\mathrm{SPS}^{24}$ The social support factor is also correlated with the SHS $(r=0.30)$ and the MHI-5 $(\mathrm{r}=0.26)$ scales. There was a marginal significant negative correlation between social support and vulnerability to stress $(\mathrm{r}=-0.24)$. The social support factor correlates significantly with Met $(r=-0.13)$ and Card $(r=-0.10)$, although the magnitude of both correlations is weak.

\section{DISCUSSION}

The objective of this paper was to evaluate the structural validity and the convergent validity of the first Portuguese version of the CD-RISC. Despite the importance of this construct, to date, there is no validated scale to measure resilience in the Community of Portuguese Language Countries (n.d.), ${ }^{40}$ estimated to be more than 270 million people. Resilience is a fundamental element of mental health, health assets, capabilities and positive adaptation. It enables people to both cope with adversity and reach their full potential, and influences a wide range of outcomes at individual and community levels, including 
healthier lifestyles, better Phea, improved recovery from illness, fewer limitations in daily living, higher educational attainment, greater productivity, employment and earnings, better relationships with adults and with children, more social cohesion and engagement and improved quality of life. ${ }^{41}$ It is not a surprise that resilience has been extensively measured and used to understand individual and social phenomena.

The results do not replicate the original five-factor structure; instead, the results suggest a three-factor structure with self-efficacy, spirituality and social support dimensions represented. Although this result is not consistent with the original proposal from Connor and Davidson, it is consistent with more recent studies. ${ }^{542}$ Consistent with this, the variability of factor structures found in CD-RISC has been document and owed to methodological variations, idiosyncratic samples and, importantly, to cross-cultural factors. ${ }^{43}$ We also note that, similar to the original study and to some of the following research, self-efficacy is the factor that explains the greatest variance of the original items. Still, although the results are important to understand the construct of resilience and how CD-RISC works as an instrument measuring this construct in a Portuguese sample, we note that the resulting scale should not be regarded as an improved version. In fact, we consider that improved usage of this scale would come from prior testing of the factorial structure of the original 25 items and comparison with the results of this paper and similar.

The results from the validation are, with one sole and justifiable exception, consistent with evidence from the literature. The negative association we found between the self-efficacy factor and the measures of stress is consistent with the idea that people with high-efficacy beliefs are able overcome obstacles and focus on opportunities, and are more able to perceive stressful situations as challenging rather than as problematic events. ${ }^{44}$ The positive correlations between self-efficacy and happiness and satisfaction with life are consistent with the findings in the literature where self-efficacy beliefs may regulate positive and negative emotions. In this sense, people with higher self-efficacy beliefs are less distressed and feel more capable of dealing with problematic situations. ${ }^{45}$ Recent studies have found that self-efficacy is indeed positively correlated with happiness ${ }^{46}$ and satisfaction with life. ${ }^{44}$ Although moderately, the negative correlation between the self-efficacy factor and the measures of Phea and Mcons constitutes an extension of the findings where self-efficacy is associated with increased health and life satisfaction.

The positive correlation we found between the spiritual factor and the vulnerability to stress is consistent with Connor and colleagues' ${ }^{6}$ study with survivors of violent trauma, where spirituality is proposed as a coping strategy do deal with higher post-traumatic stress disorder scores. Still, the fact that spirituality does not relate with any other variables is not consistent with the literature, where previous studies have successfully established correlations between spirituality and happiness ${ }^{47}$ and between spirituality and life satisfaction. ${ }^{48}$ The absence of effects can be a result of the low statistical power due to the small sample size in the RECT sample. In fact, a post hoc power analysis showed that the power to detect a significant correlation of 0.20 at 0.05 in our sample is only 0.28 .

Interestingly, the positive correlation we found between the social support and the $\mathrm{SPS}^{24}$ is the only significant correlation of the SPS, which supports the assumptions that this factor is a specific dimension of resilience. The positive correlations we found between the social support factor and the SHS and MHI-5 scale are consistent with the findings in the literature showing the strong impact of social support on happiness, especially from closer social circles. ${ }^{49}$ For instance, in a study with survivors from a natural disaster, the authors found that predisaster happiness and postdisaster social support were protective against the negative effect of the hurricane on survivors' postdisaster happiness. ${ }^{50}$ The negative correlation we found between social support and vulnerability to stress is consistent with the findings in the literature, in which it is becoming increasingly consensual that the lack of social support is an important risk factor in dealing with stressful and adverse life events. ${ }^{51}$ We found negative correlations between social support and Met and Card. Despite some of the literature describes a conflicting relation between social support and Phea, ${ }^{52}$ it appears that social support is negatively associated with cardiovascular death and that it protects against recurrent events, the existing research suggests the predictive relation between social support/ social networks and incidence of disease, specifically cardiovascular disease.

In summary, regarding the self-efficacy factor, we found associations with perceived stress, vulnerability to stress, subjective happiness and mental health. Additionally, we also found associations with perceived Phea and Mcons, what we consider to be an extension of the findings relating self-efficacy with health and life satisfaction. Regarding the spirituality factor, we found only an association with vulnerability to stress. This result is not consistent with the literature where spirituality has been related with stress, happiness and life satisfaction. As mentioned, the absence of effects here is likely due to low test power. Finally, regarding the Social Support Scale, we found an association with the SPS, subjective happiness, mental health and vulnerability to stress. Additionally, we also found an association with the two BIs used, specifically, Card and Met. Resilience, through its self-efficacy component, showed a protective effect on the extent of myocardial infarction by affecting the inflammatory response. ${ }^{53}$ Emotional vitality, as part of healthy psychological functioning, may protect against risk of coronary heart disease (CHD) ${ }^{54}$ Resilience could have life-saving effects. Prevention and intervention in CHD not only must involve measures to reduce psychological distress but also should focus on promoting positive emotions. 


\section{Applications for the Portuguese version of the CD-RISC}

Our study extends the literature that has provided support on the importance of the construct of resilience and, more particularly, on the use of CD-RISC as a reliable measure of this construct. In fact, using a robust psychometric method, we replicated more recent studies describing three main dimensions of resilience. Additionally, using a vast array of validated measures, we also showed how these factors were associated with scales, indexes and even behavioural measures in a way that was consistent with the literature. Importantly, these associations support the distinctiveness of the three factors, with different factors relating, as expected, with some different convergent measures. Take for instance the strong correlation between the social support factor and the SPS, and the stronger correlations between the self-efficacy factor and both stress and vulnerability to stress. A curious finding here is the specific association of self-efficacy with Phea and Mcons and the association of social support with two BIs, Card and Met.

\section{Future directions and research limitations}

Our study extends the possibility to measure and investigate resilience in Portuguese communities using a rigorously validated scale. Future studies with this community can explore further the three-factor structure of the CD-RISC and test for the convergent validity with new samples. A limitation of the current paper is the difference in test power between the two samples used to do the convergent validity. This is particularly important because the low test power sample (from the RECT project) included important and unique validation measures and because the spirituality scale did not replicate entirely the findings in the literature. Finally, and considering both research and practice, future studies with the Portuguese communities can follow the factorial structure found and validated. These studies can, again, provide additional support to the theoretical and practical relevance of resilience and its dimensions as measured by the CD-RISC.

Acknowledgements We thank Carla Crespo and Maria Violante Doria for their support in the Connor-Davidson Resilience Scale translation process, and also all the colleagues and institutions that supported us in the data collection (namely, Joana Carreiras and Susana Oliveira). We thank Professor Jonathan Davidson for his helpful feedback throughout this process of paper construction.

Contributors JF-A: responsible for the Connor-Davidson Resilience Scale translation process; substantial contribution to the conception and design of the work, acquisition, analysis and interpretation of data; drafting of the work; agreement to be accountable for all aspects of the work related with the integrity of the data analysis and results reporting; and final approval of the version to be published. Accountable for the following sections: Introduction, Method, Results and Discussion. MHdS: substantial contribution to the conception and design of the work, acquisition, analysis and interpretation of data; drafting of the work; agreement to be accountable for all aspects of the work related with the integrity of the data analysis and results reporting; and final approval of the version to be published. Accountable for the following sections: Introduction, Method, Results and Discussion. MTR: substantial contribution to the conception and design of the work, acquisition, analysis and interpretation of data; revising the work critically; agreement to be accountable for all aspects of the work related with the integrity of the data analysis and results reporting; and final approval of the version to be published. Accountable for the following sections: Introduction, Method, Results and Discussion. SM: substantial contributions to the analysis and interpretation of data for the work; drafting the work and revising it critically; agreement to be accountable for all aspects of the work related with the integrity of the data analysis and results reporting; and final approval of the version to be published. Accountable for the following sections: Method, Results and Discussion.

Funding The Health Impact Assessment of Employment Strategies project was funded by the Office of the High Commissioner for Health followed by the General Health Direction.

Competing interests None declared.

Patient consent for publication Not required.

Ethics approval This research project was reviewed by the Ethical Committee of the University of Lisbon, Faculty of Psychology, which granted authorisation to perform these studies. The second data set, which came from the Health Impact Assessment of Employment Strategies (HIAES) project in Portugal, was approved by two institutional ethical committees, the Ethics Committee for Health of the National Institute of Health Doutor Ricardo Jorge public institute and the Ethics Committee for Health of the Lisbon/North Hospital Centre of Faculty of Medicine of the University of Lisbon. This research was conducted under the Helsinki declaration code of ethics. Ethics approval was obtained for the scientific use of the data in both studies. This involves the usage of the data and publication of the results in thesis and scientific journals.

Provenance and peer review Not commissioned; externally peer reviewed.

Data sharing statement Statistical codes and data sets are available from the figshare repository (https://doi.org/10.6084/m9.figshare.7111676.v1).

Open access This is an open access article distributed in accordance with the Creative Commons Attribution Non Commercial (CC BY-NC 4.0) license, which permits others to distribute, remix, adapt, build upon this work non-commercially, and license their derivative works on different terms, provided the original work is properly cited, appropriate credit is given, any changes made indicated, and the use is non-commercial. See: http://creativecommons.org/licenses/by-nc/4.0/.

\section{REFERENCES}

1. Rutten BP, Hammels C, Geschwind N, et al. Resilience in mental health: linking psychological and neurobiological perspectives. Acta Psychiatr Scand 2013;128:3-20.

2. McCrory E, De Brito SA, Viding E. Research review: the neurobiology and genetics of maltreatment and adversity. $J$ Child Psychol Psychiatry 2010;51:1079-95.

3. Windle G, Bennett KM, Noyes J. A methodological review of resilience measurement scales. Health Qual Life Outcomes 2011;9:8.

4. Connor KM, Davidson JR. Development of a new resilience scale: the Connor-Davidson Resilience Scale (CD-RISC). Depress Anxiety 2003;18:76-82.

5. Karaırmak O. Establishing the psychometric qualities of the Connor-Davidson Resilience Scale (CD-RISC) using exploratory and confirmatory factor analysis in a trauma survivor sample. Psychiatry Res 2010;179:350-6.

6. Connor KM, Davidson JR, Lee LC. Spirituality, resilience, and anger in survivors of violent trauma: a community survey. $J$ Trauma Stress 2003;16:487-94.

7. Arias González VB, Crespo Sierra MT, Arias Martínez B, et al. An in-depth psychometric analysis of the Connor-Davidson Resilience Scale: calibration with Rasch-Andrich model. Health Qual Life Outcomes 2015;13:1-12.

8. Jung YE, Min JA, Shin AY, et al. The Korean version of the ConnorDavidson Resilience Scale: an extended validation. Stress Health 2012;28:319-26.

9. Liu DWY, Fairweather-Schmidt AK, Burns RA, et al. The ConnorDavidson Resilience Scale: Establishing Invariance Between Gender Across the Lifespan in a Large Community Based Study. J Psychopathol Behav Assess 2015;37:340-8.

10. Green KT, Hayward LC, Williams AM, et al. Examining the factor structure of the Connor-Davidson Resilience Scale (CD-RISC) in a post-9/11 U.S. military veteran sample. Assessment 2014;21:443-51.

11. Bezdjian S, Schneider KG, Burchett D, et al. Resilience in the united states air force: psychometric properties of the Connor-Davidson Resilience Scale (CD-RISC). Psychol Assess 2017;29.

12. Jørgensen IE, Seedat S. Factor structure of the Connor-Davidson resilience scale in South African adolescents. Int J Adolesc Med Health 2008;20:23-32.

13. Di Fabio A, Palazzeschi L. Connor-davidson resilience scale: psychometric properties of the italian version. . Giornale Italiano di Ricerca e Applicazioni: Counseling, 2012:5. 101-9. 
14. Khoshouei MS. Psychometric Evaluation of the Connor-Davidson Resilience Scale (CD-RISC) Using Iranian Students. International Journal of Testing 2009;9:60-6.

15. Burns RA, Anstey KJ. The Connor-Davidson Resilience Scale (CDRISC): Testing the invariance of a uni-dimensional resilience measure that is independent of positive and negative affect. Pers Individ Dif 2010;48:527-31.

16. Serrano-Parra MD, Garrido-Abejar M, Notario-Pacheco B, et al. Validez de la escala de Resiliencia de Connor-Davidson (CD-RISC) en una población de mayores entre 60 y 75 años. Validity of the Connor Davidson Resilience scale (CD-RISC) in people from 60-to-75 years old 2012;5:49-57.

17. Yu XN, Lau JT, Mak WW, et al. Factor structure and psychometric properties of the Connor-Davidson Resilience Scale among Chinese adolescents. Compr Psychiatry 2011;52:218-24.

18. Asante KO, Meyer-Weitz A. Measuring resilience among homeless youth: psychometric assessment of the Connor-Davidson Resilience Scale in Ghana. Journal of Psychology in Africa 2014;24:321-6.

19. Crespo M, Fernández-Lansac V, Soberón C. Adaptación Española de la 'Escala de resiliencia de Connor-Davidson' (CDRISC) en situaciones de estrés crónico. Behavioral Psychology / Psicología Conductual: Revista Internacional Clínica y de la Salud, 2014:219-38

20. Fujikawa M, Lee E-J, Chan F, et al. The Connor-Davidson Resilience Scale as a Positive Psychology Measure for People With Spinal Cord Injuries. Rehabilitation Research, Policy, and Education 2013;27:213-22.

21. Peng $\mathrm{L}$, Zhang J, Chen $\mathrm{H}$, et al. Comparison among different versions of Connor-Davidson Resilience Scale (CD-RISC) in rehabilitation patients after unintentional injury. African Journal of Psychiatry 2014;17:1-5.

22. Gonzalez SP, Moore EWG, Newton M, et al. Validity and reliability of the Connor-Davidson Resilience Scale (CD-RISC) in competitive sport. Psychol Sport Exerc 2016;23:31-9.

23. Prince-Embury S. et a/The Connor-Davidson Resilience Scale. In: Prince-Embury S, Saklofske DH, Prince-Embury S, Saklofske DH, . eds. Resilience in children, adolescents, and adults: Translating research into practice. New York, NY, US: Springer Science + Business Media, 2013:161-6.

24. Cutrona CE, Russell DW. The provisions of social relationships and adaptation to stress. Advances in personal relationships 1987;1:37-67.

25. Moreira JM, Canaipa R. A escala de provisões sociais: desenvolvimento e validação da versão portuguesa da 'Social Provisions Scale.'. Revista Iberoamericana de Diagnóstico y Evaluación Psicologica 2007;24:23-58.

26. Diener E, Emmons RA, Larsen RJ, et al. The Satisfaction With Life Scale. J Pers Assess 1985;49:71-5.

27. Simões A. Ulterior validação de uma escala de satisfação com a vida (SWLS). Revista Portuguesa de Pedagogia 1992;26:503-15.

28. Cohen S, Kamarck T, Mermelstein R. A Global Measure of Perceived Stress, 385, 1983.

29. Cohen S, Williamson G. In: Spacapan S, Oskamp S, Perceived stress in a probability sample of the United States. The social psychology of health: Claremont Symposium on applied social psychology. Newbury Park, CA: Sage, 1988.

30. Rocha P. Família e Trabalho: (Des)Equilíbrios que orientam a (In) Satisfação. Valor do Apoio Social e da Vinculação. Tese de Mestrado em Psicologia (Stress e Bem-Estar), FPCE, UL 2009.
31. Vaz-Serra A. Construção de uma escala para avaliar a vulnerabilidade ao Stress: a 23 QVS, 2000.

32. Veit CT, Ware JE. The structure of psychological distress and wellbeing in general populations. J Consult Clin Psychol 1983;51:730-42.

33. Ribeiro JLP. Mental health inventory: um estudo de adaptação à população portuguesa. Psicologia, Saúde \& Doenças 2001;2:77-99.

34. Lyubomirsky S, Lepper HS. A Measure of Subjective Happiness: Preliminary Reliability and Construct Validation, 137, 1999.

35. Pais-Ribeiro JL. Validação transcultural da Escala de Felicidade Subjectiva de Lyubomirsky e Lepper / Cross cultural validation of the Lyubomirsky and Lepper subjective happiness scale. Psicologia, Saúde \& Doenças 2012;2:157.

36. Tabachnick BG, Fidell LS. Using multivariate statistics : boston: pearson and allyn and bacon cop. 2007. 5th ed, 2007.

37. Campbell DT, Fiske DW. Convergent and discriminant validation by the multitrait-multimethod matrix. Psychol Bull 1959;56:81-105.

38. Cronbach LJ, Meehl PE. Construct validity in psychological tests. Psychol Bull 1955;52:281-302.

39. Field A. Discovering statistics using SPSS: and sex and drugs and rock'n'roll. 3rd edn. London: Sage, 2009.

40. CPLP (n.d.). Comunidade dos Países de Língua Portuguesa. https:// www.cplp.org/.

41. Friedli L, \& World Health Organization. Mental health, resilience and inequalities, 2009.

42. Xie Y, Peng L, Zuo X, et al. The psychometric evaluation of the connor-davidson resilience scale using a chinese military sample. PLoS One 2016;11:e0148843-10.

43. Davidson JR, Connor KM. Connor-Davidson Resilience Scale (CDRISC) Manual. 2017 www.cd-risc.com

44. Luszczynska A, Gutiérrez-Doña B, Schwarzer R. General selfefficacy in various domains of human functioning: Evidence from five countries. Int J Psychol 2005;40:80-9.

45. Bandura A. Self-efficacy. Harvard Mental Health Letter 1997;13:4

46. Erozkan A, Dogan U, Adiguzel A. Self-efficacy, Self-esteem, and Subjective Happiness of Teacher Candidates at the Pedagogical Formation Certificate Program. J Educ Train Stud 2016;4:72-82.

47. Teranishi Martinez C, Scott C. In search of the meaning of happiness through flow and spirituality. International Journal of Health, Wellness \& Society $2014 ; 4: 37-49$

48. Etemadifar S, Hosseiny RS, Ziraki A, et al. The relationship between spiritual well-being and life satisfaction in females with infertility. Women's Health Bulletin 2016;3.

49. Lee DS, Padilla AM. Predicting south korean university students' happiness through social support and efficacy beliefs. Int $\mathrm{J}$ Clin Health Psychol 2016;38:48-60.

50. Calvo R, Arcaya M, Baum CF, et al. Happily ever after? Pre-and-post disaster determinants of happiness among survivors of Hurricane Katrina. J Happiness Stud 2015;16:427-42.

51. Brewin CR, Andrews B, Valentine JD. Meta-analysis of risk factors for posttraumatic stress disorder in trauma-exposed adults. J Consult Clin Psychol 2000;68:748-66.

52. Eaker ED. Social support and physical health: understanding the health consequences of relationships. Am J Epidemiol 2005;161:297-8.

53. Arrebola-Moreno AL, Garcia-Retamero R, Catena A, et al. On the protective effect of resilience in patients with acute coronary syndrome. Int J Clin Health Psychol 2014;14:111-9.

54. Kubzansky LD, Thurston RC. Emotional vitality and incident coronary heart disease: benefits of healthy psychological functioning. Arch Gen Psychiatry 2007;64:1393-401. 